\title{
Research on Marketing Adaptability of Cross-border E-commerce under Different Cultural Symbols
}

\author{
Ying Wang \\ School of Foreign Languages, Xijing University, Xi'an, China, 710123 \\ 190444007@qq.com
}

Keywords: Cultural symbols; Cross-border E-commerce; Marketing adaptability; Research

\begin{abstract}
The cross-border e-commerce breaks the traditional pattern of foreign trade, and it makes the foreign trade enterprises are able to confront wholesalers, retailers, or even consumers directly and closely. So as to it dilutes the difference between practice and commercial space in the transaction process, but it can not avoid the difference of culture. Culture is an important basis for defining the psychological trend of consumers. It has a profound impact on the outcome of cross-border e-commerce, and it can bring various obstacles to cross-border e-commerce businesses. Therefore, in the context of cross-border e-commerce, the marketing strategies of the enterprise and the cross-cultural are coinciding highly. Therefore, it is of great practical significance to explore cross-cultural marketing strategies of cross-border e-commerce enterprises and enhance their adaptability in different cultures, which is of great practical significance for breaking barriers between enterprises and markets and promoting the development of cross-border e-commerce. In view of this, this article takes the marketing adaptability of cross-border e-commerce enterprises as the research object, and it takes different cultural conforms to different target markets as a breakthrough point. On the basis of the related theories, this paper discusses the strategy of enhancing the marketing adaptability of cross-border e-commerce enterprises in China. It is hoped that the discussion of this article will be of certain reference value to the cross - cultural e-commerce business enterprise marketing research.

The concept of Internet plus has made a good interpretation to the new features of the current economic form in China. At present, many industries in China are in the stage of optimization and upgrading, including export industries. Compared with the traditional cross-border trade, the advantages of cross-border e-commerce are very obvious. First, the cost of cross-border e-commerce is low. Both sides of the transaction can only complete transaction process through network transaction. It's benefit for saving the intermediate links in the transaction process, so that all kinds of additional costs generated by the intermediate links will be saved. Secondly, the efficiency of trade has been improved effectively. In the information age of the network, the information asymmetry between the buyers and sellers is gradually erased. Under the environment of cross-border e-commerce, buyers can easily get product information from all over the world through the Internet, and sellers can also connect to buyers through a variety of network channels in the shortest time. Therefore, it can be said that cross-border e-commerce has an obvious advantage in the global business environment of the network age.
\end{abstract}

\section{Cross-border E-commerce}

The so-called cross-border e-commerce refers to different customs trade body can be reached through e-commerce transactions platform. It is an international business, paying and clearing through the e-commerce platform and transporting goods through cross-border logistics and completing transactions.

\section{Enterprise Marketing Adaptability}

Marketing adaptability was proposed by Geroge S. Day at the 75th anniversary celebration of the Journal of Marketing magazine. He thinks that the enterprise is a complex adaptive system, with the combined effect of internal and external environment to learn and accumulate experience. In order 
to adapt to the changing environment, it can according to their own accumulated experience and learned knowledge to change their own structure and behavior actively. On the basis of this, the marketing adaptability of the enterprise is put forward. According to his theory, the so-called marketing adaptability refers to a integration of foresight, initiative, external and internal exploration ability, experimental ability and integrated coordination ability. It encourages enterprises to adjust their strategies to adapt to an extensible marketing ability which is accelerated and not regular. The new expansibility of marketing capability is composed of three capabilities, such as market warning, marketing experiments and open marketing. In the ever-changing market environment, these three self capabilities interact and restrict each other and enhance together, thus forming a complex marketing adaptation system, as shown in Figure 1.

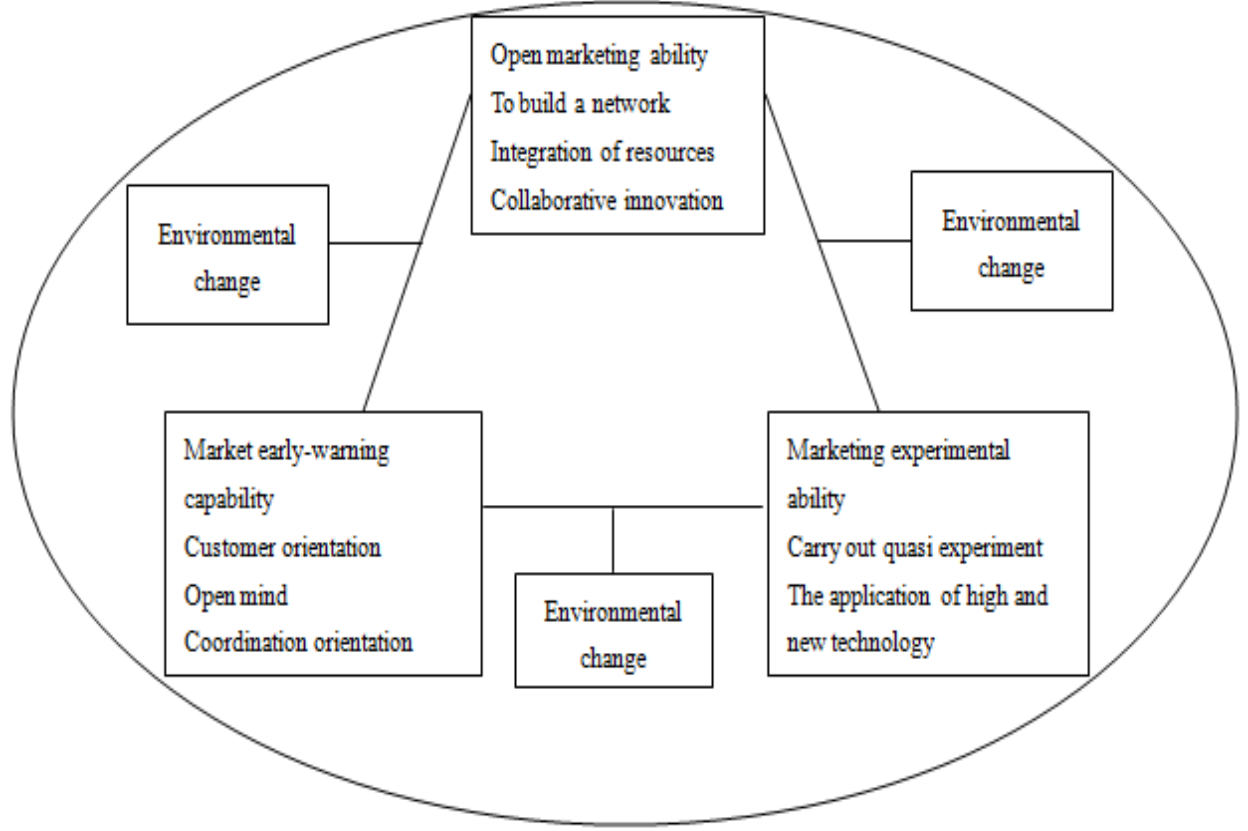

Figure 1. Conceptual model of marketing adaptability

\section{Strengthening the Adaptation Strategy of Cross-border E-commerce Marketing under Different Cultural Symbols}

Cultural symbol, is marked with a special meaning, it has a strong abstract and rich connotation. It is an abstract embodiment of the unique culture of an enterprise, a region, a nation or a country, and an important carrier and form of cultural connotations. Under the different cultural symbols, the enhancement and promotion of the marketing ability of cross-border e-commerce needs to be started from the following aspects:

First of all, because products can directly reflect the value of culture in marketing mix, cross-border e-commerce enterprises should pay attention to the language style of product description while also adopting the strategy of product marketing, and it should also pay attention to the cultural differences of different countries. The introduction of product information can not have too many modifier words, as far as possible to meet the language habits of foreign people, so as to eliminate cultural differences.

Secondly, on the cross border e-commerce website, the most expressive picture is not only intuitive expression of the main product information, but also the main way to convey corporate culture. When customers browse the website, what is most attractive to them is the color and style of the product. Therefore, cross-border e-commerce enterprises should deeply understand the national culture and customs of the target market. According to the national habits and lifestyles of different countries, a specific cultural symbol is made to sell their own products.

Thirdly, in the aspect of brand promotion, we should make full use of websites, self media and product packaging to form visual unified marketing, strengthen the overall marketing system and enhance competitiveness. Under different cultural symbols, visual marketing is the top priority. Web 
sites, online stores or e-mails, which all directly contact with consumers, will pay more attention to the visual unification of brand when they convey product information. Therefore, cross border e-commerce enterprises should aim at different culture and customs, design suitable culture for target market, conform to product marketing and promotion, and achieve the goal of visual unified marketing. Thus, it will enhance the marketing adaptability of cross-border e-commerce enterprises in different cultural backgrounds and cultural conforms.

\section{Conclusion}

The strengthening of marketing adaptability is a systematic project. The cross-border e-commerce enterprises should integrate various factors and forces under the background of different cultural symbols. From a variety of aspects of product strategy and promotion strategy, a strategic perspective is used to improve the degree of respect for target consumers. The marketing strategy and brand shaping path of marketing differentiation and visual merchandising should be worked out, so as to enhance their competitiveness in marketing and adaptability in the international market.

\section{Acknowledgement}

This research is supported by "Scientific Research Program Funded by Shaanxi Provincial Education Department (Program No.17JK1145)".

\section{References}

[1] Lisi. Oriental wisdom and symbol consumption -- the oral tea beverage advertising in DM model [M]. Hangzhou: Zhejiang Human Science Press, 2003: 170.

[2] Zhangli. Cross - border e-business background of cross - cultural marketing brand strategy selection [J]. business economic research.2015 (28).

[3] Zheng Xiaoming. An analysis of the translation of enterprise websites from the perspective of adaptation theory $[\mathrm{J}]$. Journal of western agriculture (SOCIAL SCIENCE). 2013 (10)

[4] Wu Jinya, Wang Chaoming. Intercultural communication and foreign language teaching [M]. Kaifeng: Henan Human Science Publishing.2005.

[5] Zou Liqing. Cross border e-commerce and cultural industry development strategy research [J]. cooperation economy and science and technology 2014 (11). 